\title{
A psicologia como abordagem formativa: um estudo sobre formação de professores
}

\author{
Andréa Maturano Longarezi \\ Tamarisa de Camargo Alves
}

\begin{abstract}
Resumo
O presente trabalho apresenta dados da pesquisa "A Organização do Ensino e o Desenvolvimento da Autonomia e da Afetividade na Formação e Prática Docente", desenvolvida num Centro Municipal de Educação Infantil do município de Uberaba/MG. Tal estudo configurou-se numa pesquisa colaborativa e teve como objetivo principal desenvolver um processo de formação continuada de professores. Seguindo como orientação teórico-metodológica a psicologia histórico-cultural, a pesquisa concentrou-se na elaboração, no desenvolvimento e na avaliação coletiva de um projeto pedagógico na escola. Os dados obtidos foram reveladores do movimento formativo dos professores, indicando que a formação é desencadeadora do desenvolvimento profissional docente quando empreendida no espaço de atuação do professor, tomando sua atividade principal como conteúdo. Às problematizações agregaram-se situações de instrumentalização, o que garantiu novas aprendizagens quanto à ação docente, sugerindo movimentos catárticos. Assim, alterações da prática pedagógica foram evidenciadas por algumas atividades docentes realizadas no CEMEI e que anunciaram indícios de mudanças.
\end{abstract}

Palavras-chave: Formação de professores, psicologia histórico-cultural, ensino.

\section{Psychology as a formative approach: a study on teacher training}

\begin{abstract}
This study presents data from the research "The Organization of Teaching and the Development of Autonomy and Affectivity in Teacher Training and Practice", developed in a Municipal Kindergarten Centre in the district of Uberaba - MG. This study turned out to be a collaborative research and had as its principal aim, the building of a process of continued teacher development. Following the historic-cultural psychology as the theoreticmethodological orientation, the research focused on the elaboration, development and collective assessment of a pedagogic project in the school. The collected data were revealing in the formative movement of the teachers, indicating that training triggers the teacher's professional development, when carried out in the teacher's working space, taking his/her main activity as the content. Instrumentation situations were aggregated to the problems put forward, which guaranteed new learning concerning the teacher's activities, suggesting cathartic movements. Thus, alterations in the pedagogic practice were evidenced by some teacher's activities carried out at CEMEI and they showed indication of changes.
\end{abstract}

Key words: Teacher education, historic-cultural psychology, teaching.

\section{La Psicología como abordaje formativo: un estudio sobre la formación de profesores}

\begin{abstract}
Resumen
El presente trabajo presenta datos de la investigación "La organización de la Enseñanza y el Desarrollo de la Autonomía y de la Afectividad en la Formación y Práctica Docente", desarrollada en un Centro Municipal de Educación Infantil del Municipio de Uberaba/ MG. Dicho estudio se configuró dentro de una investigación colaborativa y tuvo como objetivo principal desarrollar un proceso de formación continua de profesores. Siguiendo como orientación teórico-metodológica la psicología histórico-cultural, la investigación se concentró en la elaboración, en el desarrollo y en la evaluación colectiva de un proyecto pedagógico en la escuela. Los datos obtenidos fueron reveladores del movimiento formativo de los profesores, indicando que la formación es desencadenadora del desarrollo profesional docente, cuando es acometida en el espacio de actuación del profesor, tomando su actividad principal como contenido. Se sumaron a las problemáticas situaciones de instrumentalización, lo que garantizó nuevos aprendizajes referentes a la acción docente, sugiriendo movimientos catárticos. Así, alteraciones en la práctica pedagógica fueron evidenciadas por algunas actividades docentes realizadas en el CEMEI y que anunciaron indicios de cambio.
\end{abstract}

Palabras-clave: Formación de profesores, psicología histórico-cultural, enseñanza. 


\section{Introdução}

O presente artigo apresenta dados da pesquisa "A Organização do Ensino e o Desenvolvimento da Autonomia a da Afetividade na Formação e Prática Docente"1. Este estudo configurou-se numa pesquisa colaborativa, envolvendo as professoras de um Centro Municipal de Educação Infantil (CEMEI) do município de Uberaba/MG, juntamente com uma professora do Programa de Mestrado em Educação da Universidade de Uberaba e duas alunas de Iniciação Científica da mesma universidade, além de contar com a colaboração de duas professoras pesquisadoras de outras instituições (USP/RP e UNIMONTE/Santos), numa cooperação entre a rede municipal de ensino e a universidade.

A motivação primeira para o desenvolvimento deste estudo foi o resultado da pesquisa "Promoção de Qualidade na Educação Infantil: um programa de intervenção em formação de educadores", apoiada pela FAPEMIG, sob a coordenação internacional da Profa Júlia Formozinho (Universidade do Minho/Portugal), que identificou a fragilidade no exercício da autonomia e das relações afetivas no cotidiano da Educação Infantil.

Como referencial teórico-metodológico, a pesquisa apoiou-se na Atividade Orientadora de Ensino (Moura, 2000), cujas bases estão fundamentadas na Teoria da Atividade desenvolvida por Leontiev (1978a, 1978b). Tal abordagem tem como princípio a ideia de que a "atividade" é desencadeadora dos processos de desenvolvimento humano. Esse referencial teórico consiste numa linha de pesquisa que, junto com estudos desenvolvidos por Luria (1986, 1990, 1992), Vigotski (1991, 1993, 1995, 1996, 1998, 2000) e outros, compõe a chamada escola de Vigotski, numa abordagem histórico-cultural.

De acordo com essa perspectiva teórica, o homem desenvolve-se na situação de atividade. No caso do professor, a atividade principal é o ensino. Portanto, é na organização do ensino (aqui entendida em todo o seu processo: planejamento, execução e avaliação) que o professor pode desenvolver-se, em outros termos, formarse.

A partir dessa abordagem, a pesquisa teve como objetivo geral desenvolver um processo de formação continuada com um grupo de professoras da educação infantil, de modo a compreender as atividades que desencadeiam a formação e o desenvolvimento profissional docente, à luz dos referenciais teórico-metodológicos da Atividade Orientadora de Ensino (Moura, 2000) e da Formação Continuada de Professores em Serviço (Alvorado Prada, 1997). Esse referencial teórico definiu a organização metodológica dos encontros formativos propostos pela pesquisa, que se constituiu, portanto, numa pesquisaação, apoiada, mais especificamente, nos fundamentos metodológicos da pesquisa colaborativa, conforme definida por Garrido (1998).

1 Tal pesquisa contou com financiamento do Conselho Nacional de Desenvolvimento Científico e Tecnológico (CNPq) e dos Programas PAPE/PIBIC da Universidade de Uberaba/MG.
Desenvolvida no espaço de atuação do professor, na escola, a pesquisa constituiu um grupo no qual professorpesquisador, pesquisador-professor e aluno-pesquisador encontraram-se em colaboração, discutindo e refletindo sobre a prática pedagógica, seus limites e suas possibilidades.

Nessa perspectiva, os dados foram construídos com o grupo a partir de discussões, planejamentos, desenvolvimento de atividades didático-pedagógicas, avaliações realizadas com o coletivo das professoras, enfim, com as diferentes ações desenvolvidas pelo grupo no contexto do CEMEI. Estabeleceu-se uma relação de cooperação entre os participantes da pesquisa, a partir da qual todos colaboraram de forma direta e ativa no processo.

As dinâmicas das atividades formativas desenvolvidas comogrupofundamentaram-senaapresentaçãodesituaçõesproblema às professoras, cujas soluções impulsionaram elaborações de novos conhecimentos, referentes não apenas a determinados conteúdos, mas à prática docente de um modo geral, na dimensão da autonomia e afetividade. Essas ações buscavam soluções, atribuindo à mediação cultural papel fundamental no movimento de aprendizagem da profissão docente. Com isso, a pesquisa constituiuse também em formação continuada de professores em serviço.

Um dos princípios que orientou as atividades formativas foi o do trabalho coletivo. Entende-se, pois, que tanto o planejamento quanto o desenvolvimento e a avaliação do projeto pedagógico podem pautar-se por discussões e estratégias definidas coletivamente.

\section{Desenvolvimento Humano e Aprendizagem: uma aproximação teórica com a concepção de formação de professores}

Estudos dos processos de hominização e humanização (Leontiev, 1978b) evidenciam a natureza social do homem, revelando que seu desenvolvimento se dá na interação com o meio, tendo como principal processo desencadeador a "atividade". Segundo Leontiev (1978b), nem todos os processos de interação entre o homem e o mundo constituem-se numa atividade, apenas aqueles processos em que as necessidades são dos sujeitos e são elas que mobilizam os homens para as ações (Araujo, Camargo, \& Tavares, 2002).

A atividade consciente do homem está ligada a motivos e necessidades (Leontiev, 1978a). Partindo desse pressuposto, bem como da necessidade apresentada pelas professoras do CEMEI, percebeu-se a importância de se desenvolver um trabalho que partisse das necessidades individuais e coletivas deste grupo no seu cotidiano escolar, uma vez que a atividade principal do professor, entendida como a que desencadeia seu desenvolvimento profissional, é o ensino.

Assim, no contexto onde a pesquisa foi realizada, emergiam necessidades relacionadas à maneira de se trabalhar com os alunos desmotivados, além das próprias professoras não se envolverem totalmente, principalmente 
pelas limitações relativas aos materiais disponíveis, à infraestrutura e aos conhecimentos pedagógicos, que acabavam por comprometer a dimensão lúdica do processo ensinoaprendizagem na escola. Isso foi possível perceber com as crianças maiores em que as atividades escolares eram desenvolvidas de forma mecânica, sem explorar muito o lado afetivo e lúdico, já com as do berçário percebeuse a ausência de intencionalidade pedagógica nas ações cotidianas junto a essas crianças, restringindo o trabalho a uma dimensão do cuidar, diferente do esperado educar.

Segundo os princípios de Vigotski, as mudanças que ocorrem no homem são desencadeadas pela inserção do indivíduo na sociedade, pois dependem das relações que ele estabelece com os outros. Nesse sentido, o desenvolvimento do homem ocorre mediante a inserção em seu meio social, cultural e histórico.

Essa construção interna dos saberes é que permitirá a produção de conhecimentos e a constituição de sua própria consciência, num processo que caminha do social para o individual e, numa relação dialética, do individual para o social, compondo um movimento que parte de um plano interpessoal e se constitui intrapessoal e vice-versa. Marx enfoca que esta relação trata-se de um movimento de construção interna e externa que modifica o sujeito e o meio dialeticamente. Essa modificação se dá pelo trabalho como motor de todo processo histórico. No contexto escolar, esse processo não se constitui no isolamento, mas nas relações sujeito-sujeito, sujeito-conhecimento e conhecimentosujeito-conhecimento.

A organização da escola como espaço de ações coletivas, que desencadeiam formação e desenvolvimento em toda a comunidade escolar, pressupõe objetivos comuns ao grupo, que impulsionem o planejamento de diferentes ações, voltadas para atender as necessidades do coletivo (dimensão interpessoal). Essas necessidades são mobilizadoras do desenvolvimento intrapessoal e, portanto, transformadoras do homem e da sociedade (novamente a dimensão interpessoal), num contínuo movimento de aprendizagem e formação, cada vez mais amplo e complexo. Por esse processo, a prática social dos sujeitos (cada qual ocupando uma função social diferenciada no contexto escolar) constitui-se em Atividade e, por isso, desencadeia formação e desenvolvimento, objetivos precípuos da educação.

No decurso da atividade dos homens, o saberfazer, bem como o conhecimento desse saber, formam-se a partir da apropriação das produções histórico-culturais da humanidade. É principalmente isso que caracteriza o processo de humanização. O homem, ao agir sobre a realidade, apropria-se dos elementos naturais, transformando-os em objetos humanos (Leontiev, 1978b; Mazzeu, 1998). A apropriação da cultura modifica o homem e seu psiquismo.

Sob essa perspectiva, a aprendizagem docente (Mazzeu, 1998), desencadeadora do desenvolvimento desse profissional, precisa alicerçar-se nas condições objetivas desse sujeito e, por isso, deve partir da prática social, fundamentada nos conhecimentos prévios dos professores. Dessa forma, o processo de formação, ao partir da prática social do docente, propicia questionamentos que, sobre o olhar de Saviani (2005) e Gasparin (2005), consistem na problematização das questões teórico-práticas próprias do conhecimento imerso à prática social. Nesse sentido, enfatiza-se a busca de uma transição entre prática e teoria, entre o fazer cotidiano e a cultura elaborada. Isso possibilita a construção de um outro passo no processo de ensino-aprendizagem, a instrumentalização (Gasparin, 2005; Mazzeu, 1998; Saviani, 2005), que é o confronto do sujeito da aprendizagem com o objeto sistematizado do conhecimento, o conteúdo.

A aprendizagem se dá por uma relação recíproca e mediadora entre sujeito-conteúdo e sujeito-sujeito. Daí a compreensão da importância da interação dos indivíduos entre si com seus saberes e dos mesmos com outros instrumentos e outras fontes de saberes.

A apropriação de outros conteúdos, quando possibilita internalização e mudanças na forma de pensar e agir, pode desencadear um processo catártico no sujeito (Gasparin, 2005; Mazzeu, 1998; Saviani, 2005), expressão máxima da aprendizagem.

O objetivo do processo educativo na perspectiva histórico-crítica é o retorno à prática social, os sujeitos envolvidos no processo de ensino-aprendizagem modificam-se intelectual e qualitativamente em relação às suas concepções sobre o conteúdo que construíram e reorganizaram de forma autônoma, partindo da prática social, problematizando, instrumentalizando-se, passando pela catarse e retornando à prática social com uma nova postura prática, revelada pela nova aprendizagem (Gasparin, 2005; Mazzeu, 1998; Saviani, 2005).

$\mathrm{Na}$ perspectiva teórica do materialismo históricodialético, a prática social é o critério de verdade da pesquisa científica, essa prática não se trata de uma ação qualquer, mas de uma ação pensada e reorganizada, trata-se de uma práxis (Longarezi, 2006).

A formação continuada de professores, tal como desencadeada pela pesquisa, implica a participação e imersão do professor nos seus processos formativos, condições indispensáveis para apropriações que produzam movimentos catárticos e possibilitem mudanças significativas nas práticas educativas.

No que tange à Formação Continuada de Professores em Serviço, especificamente, entende-se que ela ocorre quando o grupo constrói novas relações com o conhecimento, passando a entender o cotidiano como o seu dia a dia de trabalho, contextualizado pelas relações de todos que dele participam (Alvorado Prada, 1997).

Considera-se que a escola, local de trabalho do professor, é o local de formação continuada de docentes, onde a discussão sobre a prática pedagógica com seus demais membros promove novas relações e possibilita a construção de novos conhecimentos. Com isso, desencadeiam-se processos formativos que, na perspectiva aqui enfocada, só são possíveis quando a Atividade de 
Ensino (Moura, 1998) assume um papel articulador e coloca o coletivo em movimento, buscando a solução de problemas, objetivando suas intenções, satisfazendo as necessidades assumidas como comuns. Isso permite, ao coletivo, assumir sua intencionalidade educativa e sua identidade, situação que pode desenvolver relações autônomas com o próprio trabalho.

Tal como aqui compreendida, a formação continuada de professores em serviço não ocorre à revelia de um desenvolvimento da autonomia profissional dos docentes. Nesse sentido, a formação de professores precisa desenvolver-se a partir de processos que a desencadeiem. A autonomia não é uma capacidade individual que depende apenas de mecanismos intrínsecos à pessoa, mas um processo que se constrói nas situações sociais (Contreras, 2002). Por essa razão, o desenvolvimento da autonomia do professor não pode ser entendido como resultado de um movimento que ocorre exclusivamente na esfera individual.

Na perspectiva da pesquisa colaborativa (abordagem metodológica que orientou o presente estudo), as discussões, as reflexões, os processos formativos assumem outra qualidade quando são construídos coletivamente, quando partem de necessidades comuns e são pensados, organizados, praticados e analisados coletivamente.

Os processos de formação realizados no local de trabalho dos professores, onde eles interatuam com outras pessoas, permitem, como discutido anteriormente, trocas de experiências e, por conseguinte, a melhoria das relações e a compreensão das situações-problema para sua transformação, possibilitando a construção de novas concepções teóricas e metodológicas de formação e de prática docente. Isso, de certa forma, confirma a hipótese de que é no contexto da escola que a formação pode partir de uma prática social e retornar a ela como possibilidade de transformação da realidade, fazendo da necessidade do coletivo da escola motivo para levantar as situaçõesproblema e buscar propostas de solução que transformem a realidade.

Assim entendida, a formação de professores em serviço "implica em envolver as experiências individuais e coletivas construídas no cotidiano do trabalho docente", a partir do desenvolvimento de projetos institucionais de formação (Alvarado Prada, 1997, p. 103). Esses projetos podem se tornar alternativas de transformação da instituição, potencializadas pela formação continuada de professores em serviço.

\section{Processos Formativos Desenvolvidos no CEMEI}

Com o intuito de apreender a prática social presente no contexto onde a pesquisa foi desenvolvida (um Centro Municipal de Educação Infantil -CEMEI- do município de Uberaba/MG), as problematizações, instrumentalizações, catarses, bem como as possibilidades e os limites construídos na busca de uma nova prática social, resgata-se aqui o movimento formativo desencadeado no CEMEI.
Nos primeiros encontros, as professoras apresentaram certa resistência, atribuída, principalmente, a algumas experiências anteriores do grupo. Muitos relataram que não gostariam que esses encontros se restringissem a discursos teóricos, sem uma relação explícita com as necessidades práticas dos professores, o que revelou a presença de uma concepção de teoria e prática como elementos desconexos. Isso não é exclusividade desse contexto educacional. Essa concepção subjaz o universo conceitual dos cursos de formação e dos contextos escolares. Com isso, a unidade teoria-prática não é percebida e trabalhada de modo a ser apreendida. Nesse sentido, é preciso novas vivências que possibilitem percebê-las para, então, torná-las realidade na prática educativa. Além disso,

os problemas analisados na escola, geralmente são de dois níveis: aqueles que o professor descobre no seu dia-a-dia, de modo intuitivo, que o docente raramente consegue aprofundar, por falta de tempo para construir uma metodologia que responda e desvende o fenômeno, e aqueles trazidos pelo pesquisador como problema externo à escola, que muitas vezes causa estranhamento dos sujeitos da pesquisa, que sentem "sujeitados", e não percebem o problema como deles e por isso mesmo, não se mobilizam. (Moura, 1998, p. 15).

Nessa perspectiva, cabe lembrar que os referenciais teórico-metodológicos da Atividade Orientadora de Ensino (Moura, 1998) e da pesquisa colaborativa (Garrido, 1998) não trabalham para levar uma teoria aos professores, tampouco para levantar dados com e/ou sobre eles, separados das necessidades da escola. A pesquisa colaborativa se efetiva na constituição de um grupo, no qual pesquisadores são professores e professores, pesquisadores, numa relação de colaboração.

A Atividade Orientadora de Ensino, por sua vez, pressupõe trabalhar o ensino, atividade principal do professor, como desencadeadora do processo formativo desse docente, de acordo com a Teoria da Atividade, de Leontiev (1978b). Para isso, parte das necessidades dos professores.

Dessa maneira, tanto a pesquisa colaborativa quanto a Atividade Orientadora de Ensino rompem com a perspectiva de trabalhar teoria e prática de forma dicotomizada e se propõem a fazer pesquisa com os professores e não sobre os professores.

A concepção de formação de professores que subjaz essa prática pressupõe que os problemas cotidianos devem ser analisados pelos próprios participantes e seus conhecimentos (saber da experiência, saber prático), contrastados com aqueles já universalmente sistematizados (saber científico). Esse contraste de saberes é considerado um avanço e uma forma humana de se aproximar da solução de problemas cotidianos através da construção de conhecimento por meio da pesquisa (Alvorado Prada, 1997, 2006), na qual teoria e prática não são tratadas como coisas separadas, assumem uma transversalidade e configuramse nas suas interfaces. Isso contribui para a construção de 
novos saberes e para a possibilidade de transformação das situações levantadas pelo coletivo.

Quanto a esse aspecto, cabe salientar o papel do pesquisador como desencadeador e mediador do processo. No grupo, ele pode articular o conjunto de ações que constituem o projeto escolar (Moura, 1998).

Nesse sentido, observou-se que a construção dos dados feita pelo coletivo de professores e pesquisadores acabou constituindo-se numa forma de compreender a atividade escolar mediante o levantamento dos problemas, a análise dos mesmos, o estabelecimento de estratégias de solução, possibilitando, assim, a construção de novos conhecimentos. Com o objetivo de desenvolver um processo de formação continuada que permitisse apreender as atividades desencadeadoras da formação e do desenvolvimento profissional de professores, a pesquisa fez uma intervenção no contexto desse CEMEI, realizando, no período de um ano letivo, encontros formativos com as professoras, a coordenadora pedagógica e, eventualmente, com a gestora.

Durante esses encontros, eram realizadas dinâmicas que permitiram a discussão e a problematização das práticas pedagógicas ali desenvolvidas. Mediante as situações problematizadas, eram realizadas mediações pelo grupo de pesquisadores que agregavam elementos às reflexões, possibilitando instrumentalizações por parte dos professores. A expectativa do grupo de pesquisa era a de que, nesse processo, as professoras se apropriassem de novos conhecimentos, passando por movimentos catárticos, transformadores de suas práticas.

Entende-se que a aprendizagem docente ocorre nesse processo de construção coletiva que, de acordo com Leontiev (1978b), se dá através da atividade do trabalho, desenvolvendo o homem, situação necessária ao seu processo de humanização.

No entanto, na realidade do CEMEl, a prática pedagógica existente antes da intervenção proposta pela pesquisa se dava de forma individualizada. Cada professora atuava de acordo com as necessidades e condições apresentadas no contexto da sua sala de aula. Não havia um projeto pedagógico das professoras, articulador de suas ações, integrador das atividades das turmas de diferentes faixas etárias, a partir do qual as professoras discutiam e planejavam ações coletivas.

Como parte das atividades propostas pela intervenção, procurou-se, mediante as mediações realizadas nos encontros formativos, evidenciar a necessidade de se pensar conjuntamente nessas questões para buscar estratégias que possibilitassem uma ação transformadora, passíveis de contribuir para o desenvolvimento e a formação das crianças e, ao mesmo tempo, do corpo docente.

As discussões realizadas com as professoras ao longo de um ano culminaram na reflexão sobre a necessidade de se elaborar, desenvolver e avaliar um projeto pedagógico na escola. Foi, portanto, realizado um levantamento considerando o previsto para que as professoras trabalhassem com as crianças em sala de aula, as metas que pretendiam atingir, o que tinham conseguido de positivo, as dificuldades pedagógicas que vinham enfrentando, bem como o que gostariam de estudar ou aprofundar.

Esse trabalho desencadeou uma discussão sobre o projeto pedagógico e, a partir daí, as professoras começaram a levantar possíveis temas para elaborarem seu próprio projeto. Procuraram uma temática que, de alguma maneira, envolvesse a criança, a família e a escola, uma vez que, além de serem esses temas concernentes com o proposto nas diretrizes municipais para a Educação Infantil, as relações resultantes da tríade criança/família/ CEMEI sempre foram apresentadas pelas professoras como problemáticas. Como resultado dessas discussões, as professoras apontaram "valores humanos" como uma das principais necessidades dos alunos e da comunidade local. Dessa necessidade, estabeleceu-se o Natal, dada a proximidade com as comemorações de final de ano, como um pretexto para trabalhar diferentes valores humanos.

De acordo com o depoimento das professoras, trabalhar o verdadeiro sentido do Natal permitiria desenvolver o espírito de solidariedade, de coleguismo, para além de uma visão consumista e mercadológica, o que envolveu valores pertinentes às necessidades daquele grupo social. Nesse sentido, ficou acordado que o projeto, através de suas atividades, deveria desenvolver um trabalho que contemplasse a cidadania, os direitos e os deveres, tomando o Natal como pretexto.

O entusiasmo do grupo de professores por esse projeto foi evidente principalmente porque o conteúdo do projeto - valores - apresentava-se como uma necessidade do CEMEI. Para o corpo docente, o respeito e os limites são aspectos pouco trabalhados pela família, situação definida principalmente pelo contexto social dessas crianças. Por isso, a escola assume um papel e tem, nesse sentido, uma relevante função social.

Contudo, quando da elaboração do plano de ações para o desenvolvimento do projeto, o grupo foi surpreendido com um documento da prefeitura municipal que definia o Natal como tema a ser trabalhado e desenvolvido como parte de um projeto previsto pela Secretaria Municipal de Educação (Seduc) para todos os CEMEls do município. A partir desse momento, a natureza do envolvimento das professoras mudou porque o projeto não revelava apenas uma necessidade desse coletivo escolar, atendia também a uma exigência da Seduc.

Entretanto, procurou-se manter junto ao corpo docente o princípio do que estava proposto, na tentativa de garantir a autoria do projeto. Nessa perspectiva, o planejamento foi elaborado em duas etapas. Na primeira, com o coletivo de professores, estabeleceram-se os objetivos e as ações que deveriam ser desenvolvidos pela escola como um todo. Na segunda, foram realizados planejamentos com a coordenadora pedagógica e as professoras de cada turma: as do berçário, do mini-grupo, maternal, pré I e pré II.

Estabeleceu-se que o projeto deveria ser desenvolvido englobando todas as faixas etárias. As professoras deram início à montagem do projeto definindo 
alguns procedimentos, materiais e estabelecendo estratégias de ação. Sugerido pelas professoras e apoiado pela coordenação pedagógica da escola, ficou previsto que as crianças menores, com três e quatro anos, trabalhariam prioritariamente com o desenvolvimento da linguagem oral, outras confeccionariam o livro da vida, sempre enfatizando como conteúdo os valores humanos. Foram planejadas, também, atividades envolvendo a música, o desenvolvimento da psicomotricidade, do corpo, da noção de cores, formas, além de atividades como a elaboração e a troca de cartões, a produção de um texto recuperando a história da creche, a confecção de uma árvore de natal coletiva, entre outras.

O desenvolvimento do projeto aconteceu ao longo de aproximadamente duas semanas, perfazendo, assim, o cotidiano da escola durante esse período. No que tange às produções ${ }^{2}$, o CEMEI passou por uma grande transformação, o que movimentou todo o coletivo escolar. Para essas ações, a mediação cultural estava assumindo papel fundamental no movimento de aprendizagem.

Após a concretização do projeto pedagógico, foi realizada, num último encontro, a avaliação do planejamento e do desenvolvimento do projeto a partir da discussão e análise de todo o processo registrado em vídeogravações. $O$ grupo assistiu à fita e discutiu o conteúdo do que foi planejado e do que foi executado. Foram analisadas as dificuldades enfrentadas, bem como a mudança qualitativa no trabalho, oportunizada pelo desenvolvimento do projeto.

Alguns aspectos foram particularmente destacados como a importância do trabalho coletivo que envolveu professores e alunos de diferentes turmas e de diferentes turnos, a relevância do espírito de construção coletiva desencadeado no CEMEI, a motivação e o envolvimento dos alunos nas atividades e, fundamentalmente, a materialização do objetivo que mobilizou o projeto (desencadear um ambiente e o exercício da solidariedade e do respeito ao outro).

Nesse contexto, o grupo discutiu como o projeto assumiu outra conotação quando da inferência da prefeitura nesse processo. Isso criou duas situações específicas. Comprometeu, em parte, a autoria do projeto, pois as ações desenvolvidas em alguns momentos pareciam estar para atender às solicitações da Seduc, o que acarretou uma segunda situação: um certo clima de competição entre os CEMEls. Foi anunciado que a Seduc realizaria uma visita a todas as unidades para eleger aquela que estivesse mais bem decorada, situação que acabou não ocorrendo, revelando o descaso e o descompromisso de algumas autoridades públicas com o trabalho das unidades escolares.

De qualquer maneira, a avaliação do projeto foi sobremodo significativa no processo de formação continuada das professoras em serviço, visto que possibilitou uma série de discussões sobre o cotidiano escolar, sobre o trabalho coletivo, sobre a atividade de ensino e, fundamentalmente, sobre a própria prática.

Planejar, desenvolver e analisar o projeto pedagógico

2 Enfeites; decoração das salas de aula e da escola como um todo; confecções das árvores de natal, dos cartões; entre outros. foi entendido, nesse processo, como "atividade", tal como se tem defendido, pois o projeto de trabalho desenvolvido pelo grupo foi tomado como "organizador das ações na atividade escolar" (Araujo e cols., 2002, p.6). Isso foi entendido, na análise do processo de formação proposto pela pesquisa, como atividade desencadeadora da formação e do desenvolvimento docente.

\section{Desenvolvimento profissional docente: um olhar para os processos formativos desenvolvidos}

As situações formativas desencadeadas pela pesquisa sinalizam importantes aspectos relativos à constituição da identidade profissional e pessoal do professor; à relação que ele tem com o próprio trabalho e com o previsto institucional e burocraticamente; à relação de autonomia individual e coletiva; ao desenvolvimento profissional docente; enfim, à formação desse professor, desencadeada por projetos dessa natureza.

O processo formativo desenvolvido tomou, conforme visto, a Atividade Orientadora de Ensino (Moura, 2000) como desencadeadora da formação docente, a partir da qual o planejamento, o desenvolvimento e a avaliação da prática pedagógica foram objetos da formação durante todo o decorrer da pesquisa. Partiu-se da prática social (Gasparin, 2005 e Mazzeu, 1998) quando se priorizaram as necessidades postas pelas professoras como necessidades do CEMEI, da comunidade, das crianças/alunos e de suas famílias. Tomadas como conteúdos do processo formativo, tais necessidades foram sendo problematizadas pelo coletivo de professores, juntamente com o grupo de pesquisa.

Às problematizações agregaram-se situações de instrumentalização a partir da apresentação de elementos que permitiram a apropriação de outros conhecimentos, garantindo novas aprendizagens quanto à ação docente. No que tange aos aspectos abordados durante a pesquisa, pôde-se identificar movimentos catárticos (Gasparin, 2005 e Mazzeu, 1998) e de transformação da prática social apreendidos por algumas atividades docentes realizadas no CEMEI que anunciaram indícios de mudanças.

Saviani (2005) discute o processo de ensinoaprendizagem a partir da proposição desses cinco passos: prática social, problematização, instrumentalização, catarse e nova prática social. Essa proposta pedagógica (Gasparin, 2005 e Mazzeu, 1998) compreende os processos de aprendizagem tanto de alunos como de educadores e, nesse sentido, são desencadeadores da aprendizagem discente e/ ou docente.

Essa é uma construção complexa e que pressupõe um projeto institucional de formação continuada de professores em serviço, desenvolvido dentro dos pressupostos apresentados, com a mediação do outro, no próprio contexto onde a ação educativa se efetiva.

Portanto, a escola, espaço de trabalho do professor, é, por excelência, o lugar de formação profissional docente, pois nela os professores interagem entre si, trocam ideias 
sobre suas histórias, culturas, necessidades, desejos, intenções e adquirem, por meio desses valores, saberes historicamente acumulados sobre conteúdos e sobre a prática pedagógica.

Pimenta, ao discutir a relação entre projeto pedagógico e identidade da escola, afirma que:

... não apenas é possível, como necessário compreendermos as diversas identidades das escolas, pois essa é a base que diferenciam seus projetos pedagógicos. Ou seja, o modo como operacionalizam suas propostas para atingir as finalidades da educação escolar. Eessa operacionalização se articula diretamente com os contextos, com suas realidades peculiares, suas possibilidades, suas características (das pessoas/profissionais que compõem seu universo). O que aponta para a identidade no plural. (Pimenta, 1999, citado por Araujo e cols., 2002, p. 9).

No contexto da pesquisa, o processo formativo partiu, como apresentado anteriormente, de um levantamento, junto às professoras, das necessidades do grupo, a partir das quais foi elaborado e desenvolvido o projeto pedagógico. Dessa forma, a atividade organizou o contexto escolar ao articular os sujeitos e eleger uma necessidade comum a todo o grupo que mobilizou ações educativas, cuja intencionalidade pedagógica também foi coletiva.

A formação continuada, tal como aqui abordada, efetivou-se com a troca de experiências no espaço de trabalho do professor (a escola), uma vez que a formação e o desenvolvimento profissional docente alicerçam-se a partir da construção coletiva de conhecimentos, possibilitadas pelo confronto dos saberes da experiência com os universalmente sistematizados (Alvorado Prada, 1997).

A formação de professores, nessa perspectiva, favorece a construção de conhecimentos a partir do reconhecimento dos saberes experienciais e a constituição do coletivo que aproxima, cria laços, vínculos e faz com que os sujeitos reflitam, individual e coletivamente, sobre suas práticas e, a partir delas, construam novos conhecimentos.

Tanto a abordagem da Formação Continuada de Professores em Serviço (Alvorado Prada, 1997) quanto a Atividade Orientadora de Ensino (Moura, 1998) fundamentam-se no respeito pelo saber e pelo trabalho do professor, propondo-se a estudar as situações do cotidiano com os outros, ou seja, construindo, analisando e alterando a realidade de forma coletiva.

Uma melhor compreensão, por parte dos professores, dos conceitos e das práticas educativas que permeiam a ação docente no seu espaço cotidiano de trabalho é fundamental, uma vez que é ele, o professor, quem faz a educação, organiza atividades de ensino e desenvolve o processo de ensino-aprendizagem.

O que motiva o sujeito é a necessidade e é esta que gera nos sujeitos um plano de ação que lhe permite concretizá-la. O ser humano orienta-se por objetivos, agindo de forma intencional por meio de metas e ações planejadas, como "uma forma complexa de relação homemmundo", desenvolvidas por todos em um sistema coletivo, cooperativo; o que caracteriza a educação na escola como atividade (Moura, 1998, p.4).

Esse movimento não se dá no isolamento, ele é um processo de construção coletiva e, por isso, envolve "relações entre os seres humanos e destes com o meio que os rodeia." (Alvorado Prada, 1997, p. 60-61).

A pesquisa desenvolvida no CEMEI possibilitou a consolidação de relações entre os diferentes membros da comunidade escolar, o que permitiu a construção de novos conhecimentos sobre a prática pedagógica, numa proposta fundada no princípio do trabalho coletivo e tomando o projeto como Atividade que organiza o ensino e é desencadeadora do processo de formação continuada de professores.

À medida que a pesquisa foi sendo desenvolvida, fundamentada nesses aportes teóricos (o da Formação Continuada de Professores em Serviço e o da Atividade Orientadora de Ensino), foi também os revelando, permitindo apreender que o professor forma-se no seu local de trabalho, a "atividade" principal docente é o ensino e é essa "atividade" que permite ao professor desenvolver-se profissionalmente.

\section{Considerações Finais}

No decorrer dos encontros formativos, quando a atividade de ensino foi percebida como núcleo da ação educativa a partir da qual professor e aluno constroem conhecimentos, o referencial teórico-metológico utilizado foi se concretizando na prática cotidiana da formação proposta, bem como a Atividade Orientadora de Ensino emergiu do contexto de trabalho das professoras e provocou o processo de formação.

Embora parte da identidade com o projeto pedagógico tenha ficado comprometida quando passou a ser, também, uma determinação da Seduc, o objetivo com as professoras do CEMEI, em vários aspectos, foi alcançado, principalmente no que tange à apresentação do tema, à organização, à elaboração das atividades individuais e coletivas, à execução dessas atividades e à avaliação com as professoras do que foi por elas planejado e desenvolvido. Pôde-se perceber, nas professoras, um princípio de autonomia nas suas atividades cotidianas que deverá concretizar-se em longo prazo.

A partir da perspectiva teórico-metodológica da formação docente que se tem empreendido em termos de pesquisa (Alvorado Prada, 1997, 2006; Araujo e cols., 2002; Leontiev, 1978b; Longarezi, 2006; Moura, 1998; entre outros), entende-se que as necessidades apresentadas no contexto da escola, espaço privilegiado de formação, são desencadeadoras de ações que, articuladas por um projeto, permitem concebê-lo como atividade e, para o que se propôs, desencadeadoras de novas relações com o conhecimento, com a prática pedagógica, com os demais membros da escola; novas relações que possibilitam a formação desse profissional e isso é construído em meio às complexidades que caracterizam o cotidiano do fazer docente. 


\section{Referências}

Alvorado Prada, L. E. (1997). Formação Participativa de Docentes em Serviço. Taubaté, São Paulo: Cabral Universitária.

Alvorado Prada, L. E. (2006). Pesquisa coletiva na formação de professores. Revista de Educação Pública, 15(28), 101-118.

Araujo, E. S., Camargo, R. M. de., \& Tavares, S. C. A. (2002). Formação Contínua em Situações de Trabalho. O Projeto como Atividade. Em Anais do Encontro Nacional de Didática e Prática de Ensino (pp. 1-14). Goiânia: ENDIPE.

Contreras, J. (2002). A autonomia de professores. São Paulo: Cortez.

Garrido, E. e cols. (1998). A pesquisa colaborativa na escola como abordagem para o desenvolvimento profissional de professores. Painel apresentado no IX Encontro Nacional de Didática e Prática de Ensino. Águas de Lindóia: ENDIPE.

Gasparin, J. L. (2005). Uma Didática para a Pedagogia HistóricoCrítica. (3a ed.). Campinas: Autores Associados.

Leontiev, A. N. (1978a). Actividad, Consciência e Personalidad. Buenos Aires: Ciências del Hombre.

Leontiev, A. N. (1978b). O desenvolvimento do Psiquismo. Lisboa: Horizonte Universitário.

Longarezi, A. M. (2006). Práxis e formação de professores: aspectos relevantes para se pensar uma epistemologia da formação docente. Revista Educação \& Linguagem, 14, 157-175.

Luria, A. R. (1986). Pensamento e Linguagem: as últimas conferências de Luria. Porto Alegre: Artes Médicas.
Luria, A. R. (1990). Desenvolvimento Cognitivo. (2a ed.). São Paulo: Ícone.

Luria, A. R. (1992). A construção da mente. São Paulo: Ícone.

Mazzeu, F. J. C. (1998). Uma proposta metodológica para a formação continuada de professores na perspectiva históricosocial. Caderno Cedes, 44, 59-72.

Moura, M. O. de. (1998). A educação escolar como atividade. Em Anais Encontro Nacional de Didática e Prática de Ensino (pp. 510-528). Águas de Lindóia: ENDIPE.

Moura, M. O. de. (2000). O educador matemático na coletividade de formação: uma experiência com a escola pública. Tese de Livre Docência, Faculdade de Educação, Universidade de São Paulo, São Paulo.

Saviani, D. (2005). Pedagogia histórico-crítica: primeiras aproximações. Campinas: Autores Associados.

Vigotski, L. S. (1991). Obras Escogidas. Tomo I. Madri: Visor.

Vigotski, L. S. (1993). Obras Escogidas. Tomo II. Madri: Visor.

Vigotski, L. S. (1995). Obras Escogidas. Tomo III. Madri: Visor.

Vigotski, L. S. (1996). Obras Escogidas. Tomo IV. Madri: Visor.

Vigotski, L. S. (1998). A Formação Social da Mente. São Paulo: Martins Fontes.

Vigotski, L. S. (2000). Pensamento e linguagem. São Paulo: Martins Fontes.
Recebido em: 10/08/2008

Reformulado em: 06/07/2009

Aprovado em: 16/07/2009

\section{Sobre as Autoras}

Andréa Maturano Longarezi

Doutora em Educação Escolar pela Universidade Federal de Uberaba.

Tamarisa de Camargo Alves

Graduada em Pedagogia pela Universidade de Uberaba.

Financiado pelo CNPq e pelos programas PAPE/PIBIC da Universidade de Uberaba. 